\title{
Nutritive influences on the distribution of dry matter in the plant'
}

\author{
R. BROUWER
}

Institute for Biological and Chemical Research on Field Crops and Herbage, Wageningen, Netherlands

\section{Summary}

The distribution of dry matter over the various organs of a plant is essentially due to the relative growth rates of these organs. Since growth depends on the availability of various essentials to the growing tissues, correlation seems to be a question of competition. It is true that the co-ordination is controlled in a very complex way. Both hormonal control and nutritive features play a role, the latter being the most important in agricultural practice.

Although no satisfying picture has hitherto been obtained, it is clear that it is possible to forecast the effect of many external conditions.

Increasing mineral supply tends to increase shoot growth relative to root growth; increasing water supply has the same effect; increasing light intensity promotes root growth at the expense of shoot growth.

The manner in which these distribution patterns are effected is described in the present paper.

\section{Introduction}

Everyone is familiar with the favourable effects of mineral nutrients on plant growth. It is almost equally well-known that mineral deficiency leads to a relatively more important share of the root system in the total mass of the plant. Such expressions as "the plant is seeking nitrogen" are based on this phenomenon, which is best known from nitrogen.

Its physiological background is of a general kind. Some attention is paid to this problem in most textbooks on plant physiology or morphogenesis (CURTIS and ClarK, 1950; LoOMIs, 1953; MEYer and ANDERSON, 1952; SinNotT, 1960). Whereas nutrition represents only one of the factors influencing the distribution of dry matter in the plant, in agricultural practice it is the most mportant factor. It would therefore seem very important to have a better understanding of the manner in which it acts.

An organ that does not produce or contain food must depend for its growth on one that does. There must obviously be a correlation of this sort between roots and shoots. The root/shoot-ratio therefore seems suitable for the study of correlation phenomena and the factors that modify them. As early as 1894, KNY cut off parts of the roots and/or the shoots from growing seedlings. As long as a considerable amount of reserve food was available in the seed, excision of one part only slightly affected the growth of the other. Removal of the shoot of the young seedling some-

1 Lecture held at the course "Fundamentals of dry-matter production and distribution" organized by the Royal Netherlands Society for Agricultural Sciences, Wageningen, 11th January, 1962. 
times results in a stimulated growth of the root. This seems to be due to a reduced competition for the food stored in the seed.

In older plants, however, a fairly close balance can be found between root and shoot and will be described in this paper as a functional equilibrium. The shoot/ root-ratio changes during development, shoot growth being faster than root growth. This changing ratio is of considerable theoretical interest as bearing on the functional equilibrium.

\section{Mineral nutrition}

The various mineral elements essential for growth are usually absorbed from the soil by the roots. The shoot depends on the roots as far as their mineral supply is concerned. Deficiency of a mineral essential to the growth of any organ will always restrict the growth of that organ. This is both true of the shoot and the roots. Nitrogen, for instance, is necessary for the synthesis of proteins and consequently for growth. It seems likely to be more deficient in the shoots than in the roots as the shoots are further away from the region of supply. When the supply is suboptimal shoot growth will be checked sooner than root growth and a relatively increased share of the root weight in the total weight will be obtained. Various authors have described the ultimate result of such treatments (TABLE 1).

TABLE 1. Influence of nitrate supply upon the shoot/root-ratio of barley plants (56 days old) (From TURNER, 1922)

\begin{tabular}{lccccc}
\hline & \multicolumn{3}{c}{ Dry weight } & $\begin{array}{c}\text { Shoot/root- } \\
\text { ratio }\end{array}$ \\
\cline { 2 - 4 } & & total plant & shoots & roots & \\
Low nitrogen $\ldots \ldots \ldots \ldots \ldots \ldots$ & 963 & 824 & 139 & 5,9 \\
Medium nitrogen $\ldots \ldots \ldots \ldots \ldots \ldots$ & 1398 & 1258 & 141 & 8,9 \\
High nitrogen $\ldots \ldots \ldots \ldots \ldots \ldots$ & 1413 & 1279 & 134 & 9,3 \\
\hline
\end{tabular}

When the nitrogen supply is increased the shoot/root-ratio increases owing to increasing shoot growth with only small differences in root growth. In other cases shoot growth increases when the nitrogen supply is increased, and root growth decreases at the same time. The exact nature of this response depends on other conditions. Very little is known about the direct response of the plant and the growth of its organs when changes occur in the nutrient supply, although the underlying physiological mechanism can only be explained by such experiments.

When maize seedlings are grown on Hoagland nutrient solution a constant shoot/ root-growth ratio of about 3 is maintained over a period of 2 to 3 weeks (BrouwER et al., 1961). Shoot and root fresh weights scatter around the line with only very small deviations (FIG. 1a). At the weights indicated by the arrow, part of the plants shown in the graphs as open and filled dots were transferred to solutions without nitrogen. Root growth appears to be enhanced two days and more after omitting nitrogen and this is also true of the growth of the roots relative to that of the shoot.

Similarly, shoot growth is enhanced when nitrogen-deficient plants are supplied with this element (FIG. 1b). In this case there is a more immediate response and root growth is checked almost completely until the shoot/root-ratio is about 3, which is normal under these conditions. The change-over from minus nitrogen to plus nitro- 
FIG. 1. Changes in shoot/root-relationship, based on fresh weights, of maize plants: a. previously supplied with nitrogen after transfer to solutions without nitrogen and $b$. after adding nitrogen to initially nitrogen-free solutions
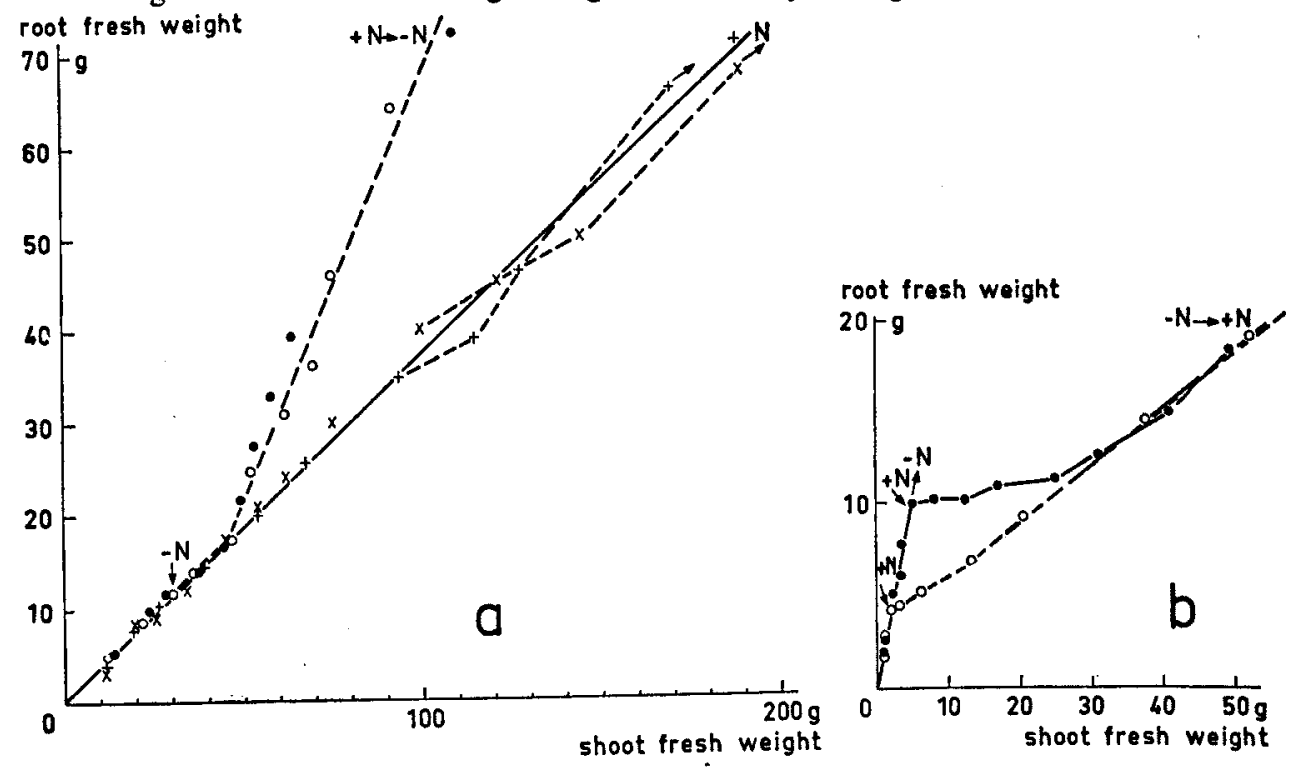

gen changes the growth pattern in such a way that the shoot/root-ratio soon increases to the value found for the plus nitrogen treatment (compare FIGs. 1a and 1b). Thereafter, growth proceeds in such a way that this value of the shoot/root-ratio is maintained.

The dry-weight percentages in the shoots change concomitantly with the variation in growth pattern (FIG. 2). After nitrogen has been omitted the dry-matter content increases, this being mainly due to an increased accumulation of sugars. After the change-over from minus nitrogen to plus nitrogen these sugars are rapidly consumed in the process of growth. The check in shoot growth resulting from a deficiency of nitrogen restricts utilization of carbohydrates by the shoots themselves. The carbohydrate supply to the roots increases and root growth is enhanced because sugar is frequently a limiting factor for root growth. Hence, the enhanced root growth is not directly due to lack of nitrogen but only indirectly via the sugar balance of the plant.

This can be made clear by experiments with different light intensities (FIG. 3). When nitrogen is present in the supply there is almost proportionality between growth and light intensity. At the lower light intensity the effect of nitrogen results in a relatively and absolutely faster root growth after the omission of nitrogen. In the presence of nitrogen root growth is then limited by the carbohydrate supply and since the omission of nitrogen checks shoot growth, the roots obtain an extra supply of sugar as a result. At the higher light intensity root growth is only favoured by nitrogen shortage when the growth is considered relative to that of the shoot.

Other mineral elements, e.g. phosphorus, show exactly the same response. It is important to note that in all cases variations in shoot/root-ratios originate from variations in the internal mineral status of the plants as induced by the treatments, and therefore only indirectly depend on the presence or absence of the nutrients in the medium. 


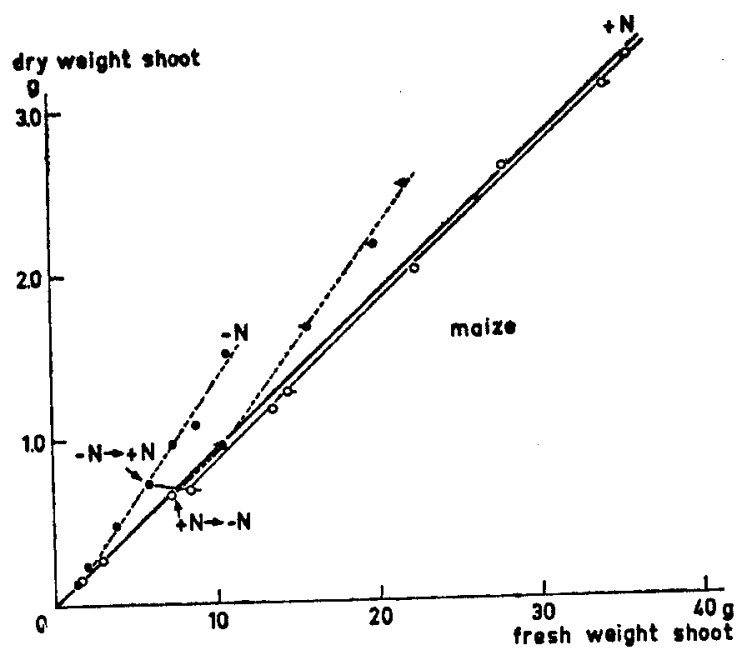

Fio. 2.

Fresh and dry weights of shoots of maize plants when the nitrogen supply is changed

Fig. 3. Root fresh weight of rye plants versus shoot fresh weight at two light intensities
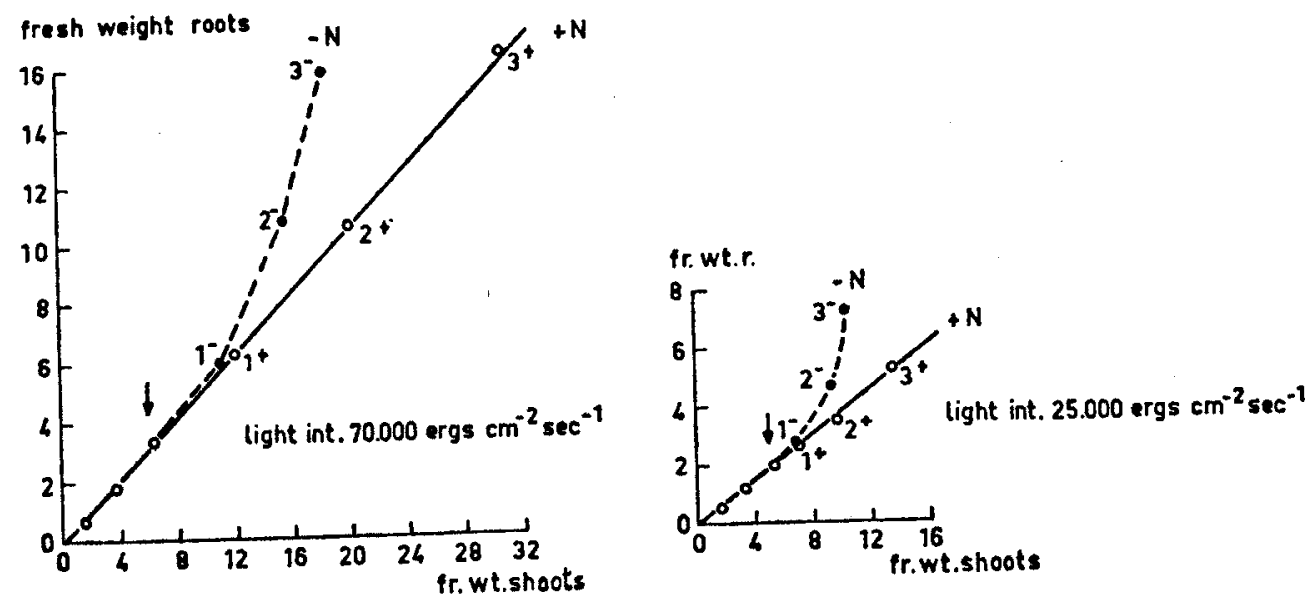

Open dots: plants grown on nutrient solutions with nitrogen.

Black dots: at weights indicated by arrows the nitrogen was withheld from a part of the plants. Numbers $1-3$ refer to subsequent harvests.

In both cases minus $N$ causes a relatively increased root growth; root growth is absolutely increased with the lower light intensity only (right).

This statement seems to contradict the results of experiments on the placement of fertilizers.

Generally speaking it has been found that the placement of fertilizers induces abundant root growth in fertilized regions. More careful experimentation as performed by GoedewAagen (1955), revealed, however, that the differences in root density decrease with increasing supply. He grew oat plants in such a way that the roots were able to divide themselves over two halves of a container, one without phosphate and the other with increasing amounts of phosphate. The relative amount of 


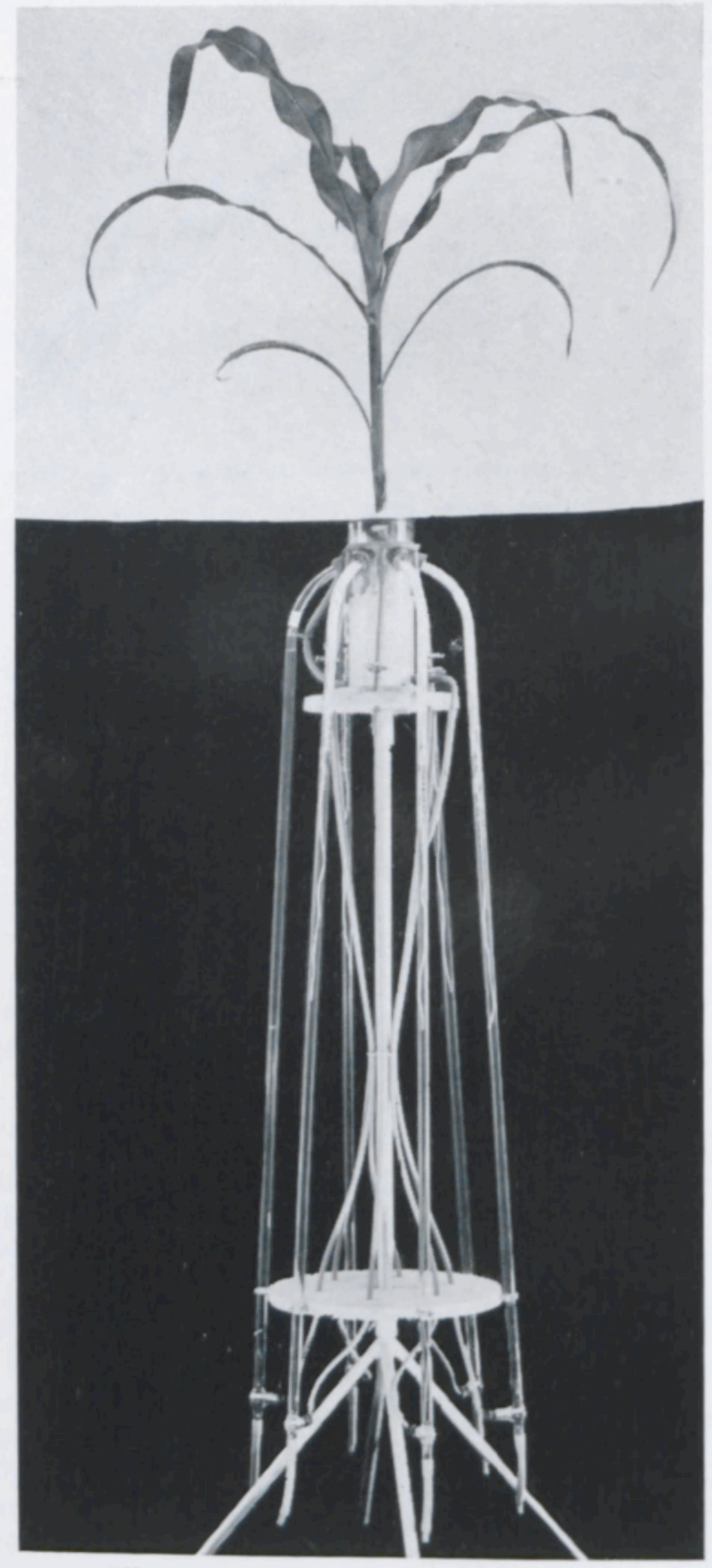

FIG. 4. Set-up for measuring growth and uptake of individual crown roots of maize plants 
roots growing in the unfertilized part of the container increased according to the phosphate dressing in the other part. It seems reasonable to expect that with higher dressings than those used by GoEdewaAgen (600 kg $\mathrm{P}_{2} \mathrm{O}_{5} / \mathrm{ha}$ ) the difference would disappear altogether.

The probability of this was shown by the following experiment in water culture. In the set-up shown in FIG. 4 (further details are given by BROUWER and LOEN, 1962) the individual crown roots of a maize plant are grown in separate glass tubes. The growth and branching of these roots can be studied in different solutions. When the overall nitrogen supply of the plant is abundant, growth rate and side-branch formation is independent of the presence or absence of nitrogen in the medium of the particular root under study. If, however, the plant as a whole suffers from nitrogen deficiency, the presence of nitrogen in the environment of the individual root is very important (FIG. 5). In the former case the transport of nitrogen from

Fig. 5. Growth and uptake of individual crown roots of nitrogen-deficient maize plants as well as plants abundantly supplied with nitrogen. Comparison of individual roots with and without nitrogen in their environment

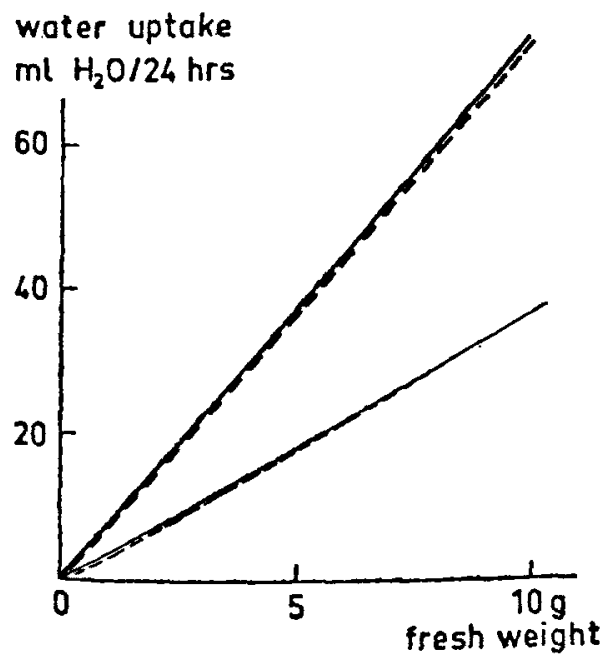

cm root length

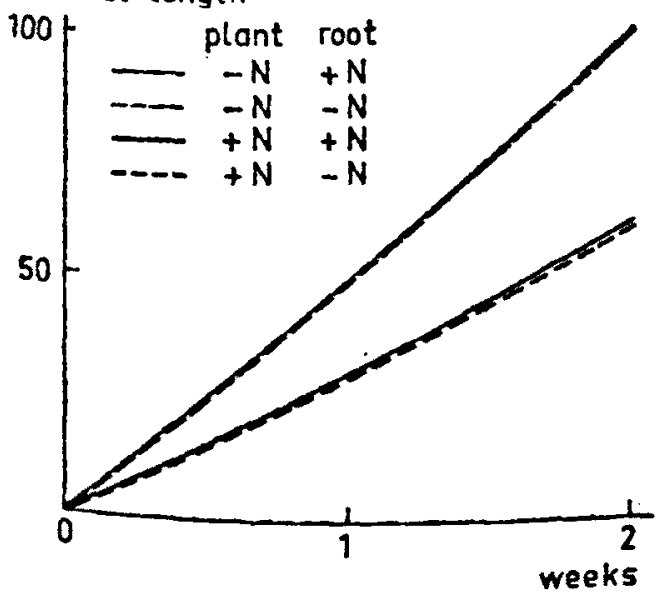

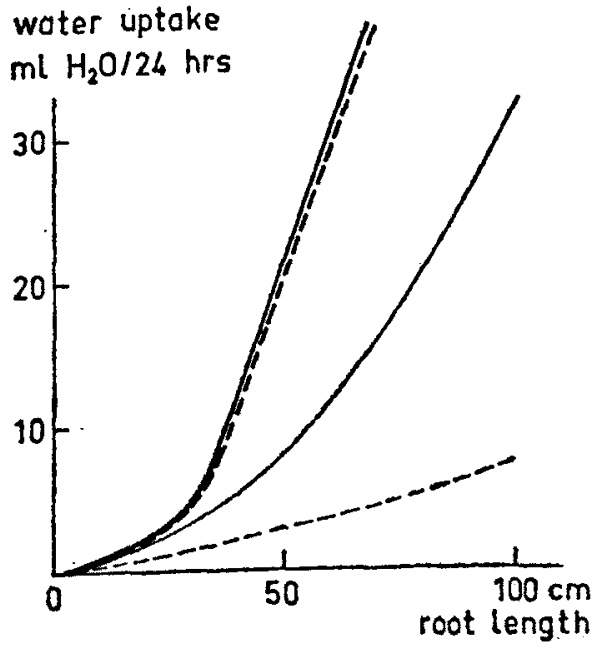

9 fresh weight

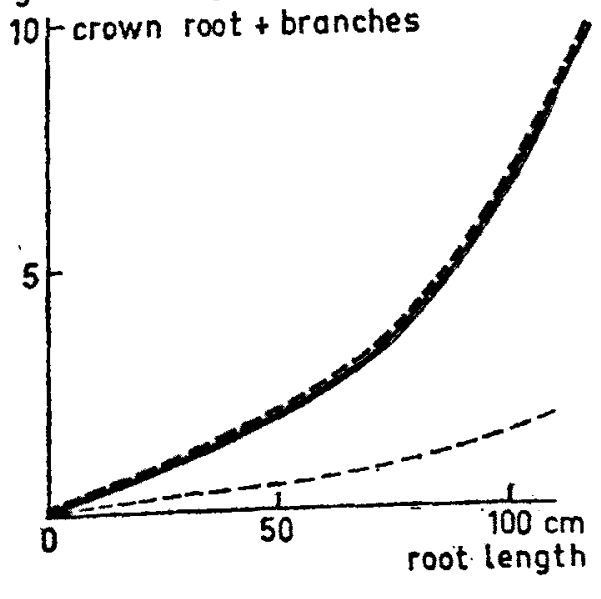

Neth. J. agric. Sci., Vol. 10 (1962) No. 5 Special Issue 
the shoot obviously keeps pace with the carbohydrate supply. In the latter case the growth of the root itself is inhibited by nitrogen-deficiency.

\section{Water supply}

The effect of soil moisture content on plant growth has been the subject of a great number of investigations. An example of the influence of soil-moisture content on shoot and root growth is given in TABLE 2 .

TABLE 2. Influence of moisture content of sand on fresh weight of shoots and roots of corn seedlings (From Harris, 1914)

\begin{tabular}{ccccc}
\hline $\begin{array}{c}\text { Soil-moisture } \\
\text { content }\end{array} \%$ & \multicolumn{3}{c}{ Fresh weight in $\mathbf{g}$} & $\begin{array}{c}\text { Shoot/root- } \\
\text { ratio }\end{array}$ \\
\cline { 2 - 4 } 11 & total plant & shoots & roots & \\
15 & 5,86 & 1,56 & 4,30 & 0,36 \\
20 & 7,25 & 2,35 & 4,90 & 0,48 \\
30 & $\mathbf{8 , 5 4}$ & 3,36 & 5,18 & 0,64 \\
38 & 7,75 & 3,54 & 4,21 & 0,84 \\
& 7,68 & 3,63 & 4,05 & 0,89 \\
\hline
\end{tabular}

Increasing the moisture content from $11 \%$ to $20 \%$ promotes both root and shoot growth. Further increases in moisture content results in decreases in root growth below the maximum at $20 \%$. This is a very general phenomenon and is often attributed to a lowering of the oxygen availability. It may be doubted, however, whether this is always the correct explanation. If one considers root growth in relation to the growth of the plant as a whole it can be seen (last column) that an increase in moisture decreases the relative root growth and increases the relative shoot growth.

A logical explanation of these changes in relative growth of shoots and roots can be given according to the same theory as that propounded in the previous chapter.

Moisture may be a limiting factor for both roots and shoots, but it is more likely to be limiting for shoots than for roots since the shoots depend on the roots for their moisture. Moreover, most of the moisture is lost from the shoots so that moisture tension is usually higher in the shoot than in the roots. It is noticeable (TABLE 2) that differences in root growth are fairly small compared with the differences in shoot growth.

When bean plants are grown on a Hoagland solution a fairly constant shoot/rootratio of about 1,7 (dependent on the light intensity) is maintained until flowering (FIG. 6). On a Hoagland solution with sodium chloride addition of up to 3,75 atm the ratio is about 1,3 . When the plants are transferred from Hoagland solution to the increased suction tension of 3,75 atm shoot growth is reduced and root growth relatively (but not absolutely) increased. On the other hand, when plants are transferred shoot growth is increased and root growth simultaneously decreased. In both cases the changes in the growth pattern are such that the ratio corresponding to the new situation is soon reached.

These responses are fully comparable with the responses to changes in the nitrogen supply (FIG. 2) and show that this is a general phenomenon. The same phenomenon 


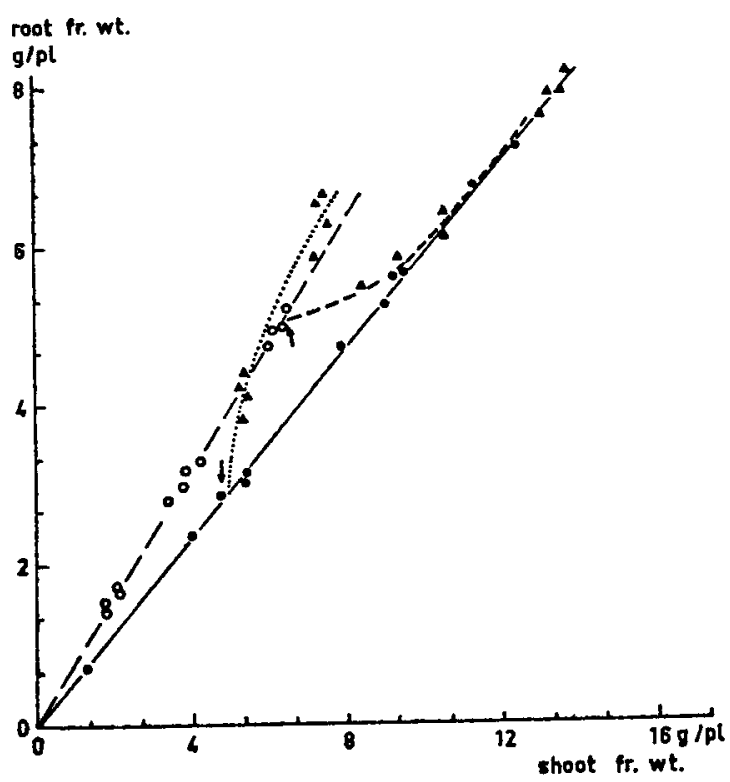

FIG. 6.

Relationship between fresh weight of roots and shoots of bean plants at various "drought" conditions

Black dots: plants on Hoagland solution all the time.

Open dots: plants on Hoagland solution with $\mathrm{NaCl}$-addition (3,75 atm).

At weights indicated by arrows a part of the plants is transfered: from Hoagland to Hoagland $+3,75$ atm $-\mathrm{NaCl}$ (black triangles) and from Hoagland + 3,75 atm - $\mathrm{NaCl}$ to Hoagland (open triangles).

can also be demonstrated when changes occur in the light intensity, causing changes in the carbohydrate supply.

\section{Carbohydrate supply}

Light intensity, light quality and duration of the light period have marked effects on the growth pattern of plants. These effects are partly due to induction of hormonally controlled changes in the type of growth. This type of response has been discussed in other papers in this series. Here we are only dealing with the influence via the carbohydrate balance. As was briefly indicated in the first paper (BRouwer, 1962), increasing the light intensity tends to increase root growth relative to shoot growth.

WASSINK and Richardson $(1951,1955)$, using an accurate measurement of root growth of Acer Pseudoplatanus, have shown that decreasing the light intensity soon results in decreased root growth. Increasing the light intensity increases the growth rate of the roots. The relation between growth rate of the individual roots and light intensity bears a fairly close resemblance to a photosynthesis curve.

Carbon dioxide-free air also decreased root growth. In these cases root growth was directly dependent on the photosynthetic activity of the shoots. In other cases where the carbohydrate supply does not limit root growth a somewhat different picture may be obtained. It is likely, however, that in young, rapidly growing plants the carbohydrates usually limit the root growth.

In WASSINK and RoBERTSON's experiments defoliating had the same effect as lowering the light intensity. In connection with our own problem it is interesting to know how the shoot growth is influenced in this case. This is shown in FIG. 7. The data are taken from experiments with bean plants. Partial defoliation results in decreased root growth and increased shoot growth. There is an obvious similarity to the nitro- 
R. BROUWER

fr. wt. leaves

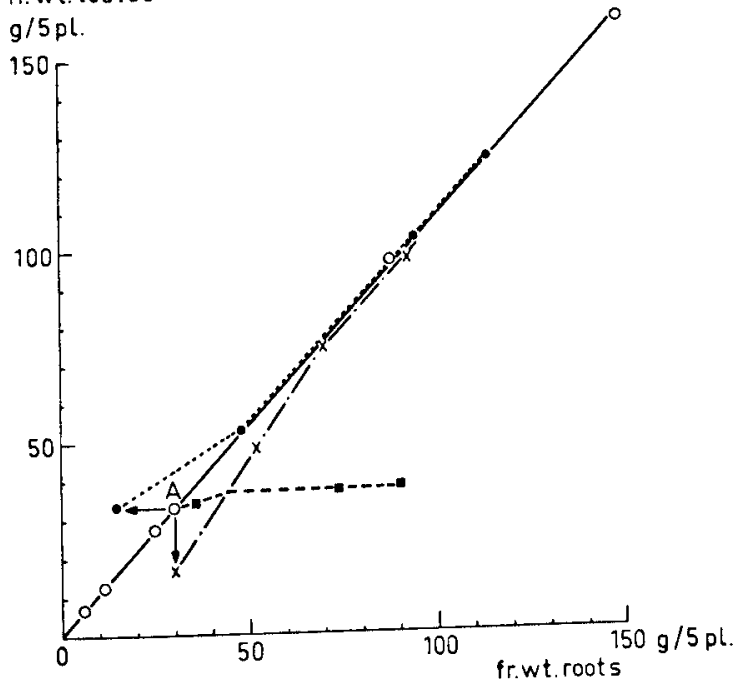

Fio. 7.

The relation between fresh weights of leaves and roots of bean plants grown on Hoagland solution in climate rooms

Open dots: normally growing plants. Black dots: plants partly derooted at point $\mathrm{A}$.

Crosses: plants partly defoliated at point $\mathrm{A}$.

Black squares: plants from which all leaf primordia above the two seedling leaves were removed continuously.

Note the rapid recovery to the basic line (open dots) after disturbance.

gen and water experiments (FIG. 2 and 5). When the original equilibrium is disturbed without changing the external conditions the equilibrium is rapidly re-established.

The light intensity does not always have a marked effect. In some cases no influence whatever was found on the distribution. It is also possible, however, that the influence is based on other phenomena. Light intensity influences both photosynthesis and transpiration. Higher light intensities increase the suction tension in the plant (Brouwer, 1961). It has often been observed that this causes a reduced growth rate (LoomIs, 1934) of the shoots. The effect may be very similar to that of increased suction tension in the root medium.

Another aspect of the light intensity is the increase in shoot temperatures compared with soil temperature in a dense crop and the reverse in thinly covered fields. These aspects will not be treated here as very little data is available.

\section{General conclusions}

As was pointed out in a previous paper, the essential materials for the growth of any tissue include carbohydrates, minerals and water. Variations in the amount of these essential materials may cause variations in the growth rate of the tissue. This can only be the case, however, when the essential material under study is the limiting factor. Since the roots depend on the shoots for their carbohydrate supply and since they are at a great distance from the leaves where the carbohydrates are produced, the latter apparently limit root growth more often than shoot growth. If this is the case, any treatment that increases the assimilation of carbohydrates or reduces the utilization of carbohydrates by the shoots themselves is likely to increase root growth.

Since the shoots depend on the roots for their supply of minerals and water, and since the shoots are further away from the region of supply than the roots, it would seem that these essential materials limit shoot growth more often than root growth. If this is the case, any treatment that increases the uptake of minerals and moisture is likely to increase shoot growth relative to root growth. 
This means that these essential materials exhibit the following pattern. When other growth-limiting factors are eliminated, shoot growth continues at a rate that depends on the minerals and moisture supplied by the roots. Root growth continues at a rate depending on the carbohydrates supplied by the shoot. In most cases there is an interaction between the two processes.

If, for instance, the mineral and moisture supply is abundant shoot growth will also be abundant. Most of the carbohydrates built up by the shoots will be utilized by the shoots and the supply to the roots is very small. Root growth is then limited by the carbohydrate supply. In such a case the amount of minerals and moisture taken up will not be increased since their uptake largely depends on extension of the root system. The supply of the growing tissue of the shoot will gradually decrease. Only a part of the carbohydrates built up in the shoots can then be utilized in the shoot and gradually more and more becomes available for the roots. Root growth witl be increased and with it the mineral and moisture uptake, the cycle being repeated. It seems, therefore, that there is a functional equilibrium between shoots and roots. All the data presented in this paper can be explained in this way. This functional equilibrium is, in fact, reflected in the constant shoot/root-ratio found for each separate set of external conditions. It is the shoot/root-ratio that fits in with these conditions. If the conditions are changed the growth pattern changes in such a way that a new equilibrium is soon reached and maintained which is adapted to the new conditions. The same is true of a disturbance of the equilibrium without a change in the external conditions, for example by cutting part

g/pl shoot fr.wt.

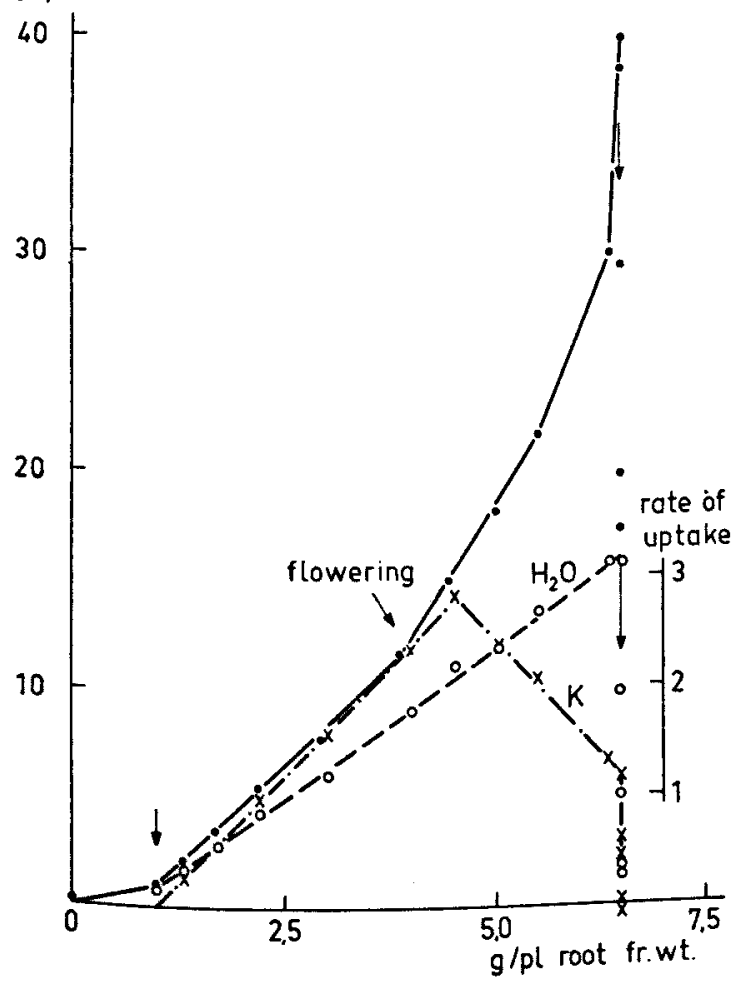

FIG. 8.

Fresh weight of shoot and rates of water and potassium uptake plotted against fresh weight of root

Note that a change of the shoot/rootratio does not go together with a change of the ratio between rate of water uptake and root weight. 
of the root system or part of the tops. In this case also a rapid re-establishment of the normal ratio is found.

It may be asked how a change in growth pattern as normally found during the growth cycle can be explained according to this theory. A reliable explanation cannot yet be given but there are many examples which show that the functional equilibrium exists in this case also. During development of the pea plant the shoot/ root-ratio changes continually, but there is no such a change in the ratio between moisture loss and root fresh weight (FIG. 8). Abcision of a part of the root system of pea plants reduces shoot growth to some extent, but the normal ratio is not established. But the proporties of leaves already present and the new leaves change in such a way as to reduce transpiration.

These phenomena do not disprove the existence of the functional equilibrium but actually support it. A great deal of research work is required to provide a satisfying picture of these growth correlations.

\section{I T ER A T U R E}

BROUWER, R.

\section{LOEN}

BrouWer, R., P. J. JeNNESKENS and $G$. J. BORGGREVE

Curtis, O. F., and

D. G. Clark

Goedewaagen, M. A. J.

HARRIS, F. S.

KNY, L.

LoOMIS, W. E.

MEYER, B. S., and

D. B. ANDERSON

SinnotT, E. W.

TURNER, J. W.

Wassink, E. C.

SON
1961 Water transport through the plant. Jaarb. I.B.S. 1961, 11-24.

1962 Distribution of dry matter in the plant. Neth. J. agric. Sci.

10, 5 Special Issue : 361-376.

1962 Growth and uptake of individual crown roots of Zea mays $\mathrm{L}$. Jaarb. I.B.S. 1962, 19-25.

1961 Growth responses of shoots and roots to interruptions of the nitrogen supply. Jaarb. I.B.S. 1961, 29-36.

1950 An introduction to plant physiology. McGraw Hill Book Cy., New York. 651-692.

1955 De oecologie van het wortelstelsel der gewassen. In: De plantenwortel in de landbouw. Staatsdrukkerij- en Uitgeverijbedrijf, 's-Gravenhage. $31-68$.

1914 The effect of soil moisture, plant food, and age on the ratio of tops to roots in plants. Jour. Am. Soc. Agron. 6, 65-75.

1894 On correlation in the growth of roots and shoots. Ann. Bot. 8, 265-280.

1934 Daily growth of maize. Am. J. Bot. 21, 1-6.

1953 Growth and differentiation in plants. Iowa State College Press, Iowa.

1952 Plant Physiology. D. van Nostrand Comp., New York. 689701.

1960 Plant Morphogenesis. McGraw Hill Book Cy., New York. 95-115.

1922 Studies on the mechanism of the physiological effects of certain mineral salts in altering the ratio of top growth to root growth in seed plants. Am. Journ. Bot. 9, 415-445.

1955 Correlaties tussen wortelgroei en bovengrondse condities. In : De plantenwortel in de landbouw. Staatsdrukkerij- en Uitgeverijbedrijf, 's-Gravenhage. 119-125.

1951 Observations on the connection between root growth and shoot illumination in first-year seedlings of Acer pseudoplatanus L. and Quercus borealis maxima (MARSH.) ASHE. Proc. Kon. Ned. Akad. Wetensch. C 54, 503-510. 